\title{
A DEUSA ISIS NAS METAMORFOSES DE APULEIO
}

\section{Anlonio Chelini}

RESUMO: Para explicar por que o escritur latino Apulcio deu à sua obra máxima o fítulo cle Asno de Ouro (Asinus Aureus), o autur discute o mpel exercidu pela decusa ĺsis nus rumus tumachus por Licio, o protagonista principal, mostrando que, como outros livros da antigüidade greco-romana, o que se narra é uma busca, a qual culmina cum a iniciaçĩo ch jovem personagem nus mistérius da ckesa cgípcia, que the restitui a forma humana (Licio havia sictu transfurmacto em asno). Esse Icma mflico-retigiuso é discutich alravés de numerusas referências ao panorama súcio-pulíticu e cultural da Roma cormopolita do lempo de Apuleio, que havia impurtado e abrigado diversas divindades estrangeiras, como a própria lsis, e agora as rejeitava, como tentaliva de revitalizar o panteão Iraclicional.

Entre os autores latinos na África, Apulcio ocupa, sem dúvida, um lugar de destaque.

Nasceu cm Madaura por volta de 125 de nossa cra e morreu cm Carlago, cm 190. Era de família proveniente da Itália, tendo o pai exercido cargos imporlantes em Madaura e, ao morrer, deixado bela herança ao fillho. Graças a tal herança, Apuleio teve oportunidade de viajar para Carlago, onde estudou. Depois loi para o Oriente, passando pela Grécia e pela Itília.

No Oriente esteve em contalo com os cultos e mislérios que fascinavam os intelecluais. Na Grécia aperfeiçoou-se na língua grega, uma vez que já a sabia e começou o estudo da retórica. Voltou depois a Roma, onde, conforme cle mesmo diz: "empreendeu o estudo e adquiriu a prática do idioma dos Lillinos, com grande sacrifício e esforço, sem nenhum professor para guiá-lo". (Apol. XXIV).

De volla a Madaura, dedicou-se à advocacia, fazendo sempre viagens para aperleiçoar-se e pesquisar.

Em Ea, Trípoli, casou-se com rica viúva. Acusado por parentes da mulher, defencleu-se, apresenlando a obra Apologio. Foi, depois, morar em Carlago, onde continuou sua vida de advogado e o estudo da relórica, da filosolia e da história natural.

Escreveu: Flórida, obra de retórica c filosofia, $O$ demônio de Sócrates $(D e$ deo Socratis), A doutrina de Platão (De Platone et eius dogmate), O Mundo (De Mundo), Apologia (Apuleius et de magia liber) e, por fim, Metamorfoses, ou $O$ Asno de ouro (Metamorphoseon ou Asinus aurens). 
Alguns autores creditam-lhe também a obra De licrburmm virtutibus (sobre as virudes das envas).

Flórida, como o próprio nome diz, ć uma antologia cm 4 volumes, onde se apresentam, sem o menor nexo lógico, notas, , textos, sentenças lïlosólicas, ancedotas e curiosidades.

O tratado sobre $O$ Demônio de Sócrates é uma compilação de obras platônicas misluradas com opiniōes e consideraçōes sobre os deuses, demônios e gènios, colhidas junto aos Caldeus. Essa obra mereceu refulação por parte de Santo Agostinho na obra $A$ cidade de Dells.

A Apologia é uma obra improvisada em poucos dias e onde se nisturam ironia, bom humor, cloquêência c erudição. É a sua obra mais pessoal.

Metamorphoseon ou $O$ Asno de ouro: célebre novela em que Lúcio, desejoso de transformar-se em pássaro, cai num grave crro, sofrendo, por isso, uma grande penilência.

Ele se dirigia à Tessália a fins de negócios e, no caminho, encontrou dois outros viajantes. Com a justificaliva de qué uma boa conversa encurla o caminho, entrou na conversa com eles. Teve sua curiosidade aguçada, quando ouviu falar de mulheres que lêm o poder de "abaixar o céu, manler a lerra cm suspensão, petrificar as Contes, dissolver as montanhas, tirar os espíritos do inferno, altingir as esirclas c iluminar o Tárlaro".

Chegando a Hípala, hospedado na casa de um conhecido do pai, acabou sábendo que a esposa desse senhor ć uma dessas leiticeiras. A cmpregada, Fólis, moça muito bonita, foi encarregada de levar as bagagens de Lúcio alć o quarto a cle destinado.

Em poucos dias ele gantha a confiança da moça c, num de desses encontros noturnos, consegue convencê-la a dar-lhe a pomada maravilhosa que o transformará em pássaro. Por engano, cle recebe outra pomada c, aplicando-a sobre o corpo, pouco a pouco, ele se transforma cm asno.

A jovem Iem a inlenção de colher pélálas de rosa que devolveriam a Lúcio a forma humana, quando, à noile, a casa ć assallada c o asno levado pelos ladrões. Mais à frente, é raplada lambém uma jovem, muito bela. Uma velha escrava foi posła em companhia da moça. Para consolar a desesperada moça a escrava conta histórias, entre as quais a de Psique c Cupido que ocupa o final do IV livro e os dois seguintes.

Depois de mil avenluras, ele consegue escapar e vai parar em Céncreas, nas costas do mar Egeu. Nesla cidade, seguindo os conselhos da deusa Ísis que Ihe aparece em sonho, ele consegue recuperar a forma humana, depois de comer as pélalas de rosa.

Há na obra passos delicados, oulros muito livres, oulros imorais.

Clouard, um dos que Iraduziram o Asinns Aureus, na introdução do seu Irabalho diz que Apulćio represenla um nome, uma obra c um mistério, pois o silêncio dos contemporâncos é absoluto a respeito do escritor alricano. 

v. 16, n. 19, p. 67-80, 1991 .

O lalim de Apulcio não \& puro, não é correto, vício comum a lodos os escrilores africanos dessa época.

O estilo é rebuscado, retórico, não deixando de empregar, a propósito ou involuntariamenle, os helenismos.

Ele gosta do efeito: nāo deixa as grandes tiradas, os dilos sentenciosos, além dâs descriçōes com muitos pormenores.

Apulcio foi um místico e, por isso, há sempre na sua obra o dualismo: artilício e religiosidade, sinceridade c dilentantismo, o que faz um paradoxo.

Somente a famosa história de Psique e Cupido daria, por si, renome ao escritor, nas palavras do já cilado Clouard.

\section{A RELIGLÃO DOS ROMANOS NO FIM DO PEKIODO REPUBLICANO}

Em menos de 150 anos a religiāo romana linhâ-se modificado bastante, nล̄o na estrutura formal, mas no substrato psicológico.

O fenomemo era nallural: na Grécia as mesnás causas linham provocado efeilos análogos. Um rilualismo basłante forçalo provocara, cm Roma, a reação das forças emotivas, principalmente por parte das mulheres, e o apelo aos rilos estrangeiros; o progresso do racionalismo, favorecendo a incredulidade nos meios cullos, nễo atinge o conjunto das superstiçōes e magias, pronlas a lomar a dianteira no primeiro momento oportuno; e, no caso de crise política ou social prolongada, essas energias, novas ou dominadas durante muito lempo, liberam-se e abalam, alé as bases, até mesmo uma religiāo instalada há muito lempo no mecanismo do Eslato.

Esse era o caso da religiāo em Roma. Os políticos vinham fazendo seus auspícios, os dos parlidos, celebrando suas feslas religiosas, mais para lins pessoais do que religiosos. $O$ cônsul Bíbulo proclamava todas as manhãis sua obmerintio (o anúncio dos presságios), cıxuanto seu colega, César, não cuidava de nada disso; a renovação dos Jogos Sagrados, a prolongaçāo das "súplicas" acabavam em proveito dos magistrados e proconsules. $O$ longo pragmatismo que, por longo lcimpo, bem soubera respeitar a religião nacional, sem tirar proveito dela, agora a fazia escrava das paixöes humanas. Por causa disso cla sofria, tanlo mais quanto a simplicidade do campo e a gasta ideologia sobre os deuses e os ritos perdiam, incessantemente, terreno diante das alraçōes urbanas oferecidas pelo culto e pelo pensamento gregos.

E esta sensibilidade, em busca de reconfortos individuais, não se encontrava nos rilos oficiais a não ser recorrendo às esperanças de salvação que somente as religiōes vindas do Oriente podiam ou iriam levar alć Roma.

Essa delerioraçăo geral não eslava nem conjurada, nem afaslada, nem era atenuada por uma política religiosa coerente. 

n. 19, p. 67-80, 1991.

A leologia artilicial imaginada pelo grande ponlífice, Múcio Cévola, bem sabia do que Iraziam a milologia e a filosofia gregas, mas não tentava fundi-las com a Iradição Romana. E, ainda mais, o que ele lentou foi somenle no campo político. O valor dos sacerdotes diminuía cada vez mais perante o povo, depois que Sula elevou para 15 o número de ponlífices, áugures e decênviros cucarregados dos assuntos religiosos; esses sacerdoles tinham ainda um certo renome místico nos meios populares o que não acontecia com os Tícios (sacerdotes cncarregados dos sacrifícios junto dos Sabinos), com os Irmãos Arvaes (grupo de 12 sacerdoles de Ceres) e com os Sálios (oulro grupo de sácerdoles), que a incompreensão e o abandono linham levado para o esquecimento. Os velhos valores mágicos pareciam um resíluo que pesava sobre lodos.

A negligência lambém ou os compromissos políticos dos pontícifes, por omissóes ou acréscimos, desorganizaram por completo o calendário a ponto de César precisar acrescentar dias para reeslabelecer a correspondência do ano com a trajetória do sol.

Muitas divindades da antiga Roma caíram no esquecimento, outras não serviam señ̃o para a devoção de pequenos grupos. E o que era mais grave: alguns dos grandes deuses eram reinvidicados por homens polílicos ambiciosos como protetores de grupos ou de pessoas. Por exemplo, Vênus, deusa da boa sorte, serviu para esse papel sucessivamente em favor de Sula, de Pompeu, de César, com os nomes de Felix ( da boa sorte), Victrix (a vencedora), Genitrix (a mãe), Vindicatrix (a vingadora), como na Fedra de Sêneca.

Trocando de alributos, cla lembrava o mundo lunar ou esiclar, o malernal ou o militar, o cósmico ou o real.

Nessa decomposição do patrimônio religioso romano, era natural que religiōes oricntais, da Ásia Menor c do Egito, ganhassem terrreno no mundo romano. Lentamente, é claro. Soldados e mercadores já as conheciam e praticavann, fosse em seus países de origem, fosse em Delos ou na Sicília, onde diversas religiōes estrangeiras já estavam começando a implantar-se ou já estavam implantadas.

Os grandes porlos da liália as acolhiam e clas cram recebidas com segurança $\mathrm{em}$ cerlos meios romanos, onde respondiam, cm parle, ìs incuietudes espirituais dos homens e mulheres a quem não mais saltisfaziam as prólicas religiosas nacionais.

Nessa matéria se vê que os pontífices e senadores não tiveram um sentimento nílido: no fundo, foram quase sempre reticenles ou, até, contradilórios.

Assim, o emprego das formas antigas, a pressão das novas necessidades afelivas, a flutuação da gestão pontifical não cram lais que certos espírilos, mesmo muito lúcidos, devessem renunciar à esperança de uma regeneração interna da religiño nacional. $O$ orgulho lambém de um domínio mundial impulsionava a uma reação contra os alluxos religiosos vindos de fora. Vemos atć, com surpresa, um arislocrala, Ápio Claudio, crer no mais irracional dos auspícios e cm todos os oulros, a ponto de ser criticado por seu colega, Cícero, no desempenho do valicínio, do augúrio. A reação lomou, sobreludo, a lorma política. 
v. 16, n. 19, p. 67-80, 1991.

No II $^{\mathbf{2}}$ livro de seu tratado sobre as leis (De legibus) Cícero formulou as prescrições religiosas permanentes do Estado Romano; Varrão compôs Antiguidade das Coisas Humanas e Divinas (Antiquitates rerum nounrum et dininarum). É um balanço impressionante de ludo o que dizia respeito à religiāo e à vida e sob o qual viveram os últimos séculos da latinidade: somente que, em muitos desses casos, seu livro evocava práticas ou nomes divinos que já não diziam mais náda para os Romanos. Nem Cícero nem Varrão comprometiam, nessas obras, suas sensibilidades religiosas ou filosóficas pessoais, mas pensavam enfrentar razoalmente o aspeclo social e nalural do problema.

Horácio, Vergílio e Tito Lívio, fosse pela poesia, fosse pela prosa, faziamse profetas que reclamavam a volla à religião e aos bons coslumes.

O comportamento tradicional (mos maiortum), os exemplos deixados pelos antepassados, as virtudes ou valores de simplicidade, pureza familiar, coragem, sobre os quais estava assentada a grandeza de Roma, vinham apresentados como corolários da restauração religiosa.

Por scu nacionalismo proclamado, a restauração religiosa de Augusto se declarava contra o progresso dos cullos provindos de fora, do Oriente, principalmente.

Se cm 43 Otávio, Antonio e Lépido, triúnviros, decidiram construir um templo oficial a Ísis, deusa provinda do Egito, e agora, em $27 / 28$, tem-se a proibição de qualquer capela particular às divindades egípcias ou orienlais, podemos imaginar o contraste dos dois comporlamentos.

Outro exemplo dessa contradição lemos, lembrando que, quando o senado ordenou a derrubada dos templos de ísis e de oulras divindades estrangeiras, foi necessário, conforme narra Valério Máximo, que Emílio Probo desse os primeiros golpes para encorajar os trabalhadores para esse serviço, uma vez que cles eslavam tomados de um temor supersticioso.

As razões políticas de oposição às influências cgípcias foram claras, os pretextos de ordem pública, aceiláveis e o lado religioso, evidente: os deuses de Alexandria e seus mistérios eram temidos; foram tolerados com cerla dificuldade alé o século primeiro d.C., quando Tibério escolheu a ocasião para desıruição de um templo e precipilação de uma estátua da deusá no Tibre. Se Augusto havia conclamado seus sucessores a zelarem pela religião de Roma, havia por parte dos sacerdotes e adeptos das deusas maior dedicação no restabelecimento dos cultos e reconstruçĩo dos templos.

Não podemos deixar de ver na conclamação de Augusto um paradoxo: enquanto Roma era chamada a se fazer sempre mais cosmopolita c capilal do Ocidente e Oriente, tenlava-se corlar a tendência que, já havia alguns séculos, tinha feito a cidade acolhedora dos cultos provindos de fora e pretendia, agora, restringir esse culto ao círculo das divindades dos antepasssados: como se o serviço a um deus estrangeiro fosse tão perigoso para o poder eslabelecido como o até́smo, a filosofia ou a prálica da magia. 
CIILiJINI, Antemio. A deusa fsis nas Metomonffases de Apulcio. I.inguin e Jileruluma, v. 16, n. 19, p. 67-80, 1991 .

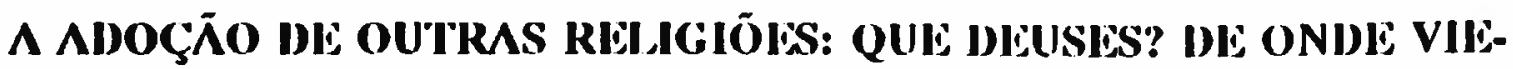 RAM? COMO FORAM RLCEIBIDOS?}

Para não falar de Deméler de Elêusis e de Dionísio cujos mistérios e cullos vieram para Roma jai bem anles, lambém cla Grécia, falcmos, agora, unicamente dos cullos de Cibele e de ísis.

Eles respondiam às mesmas aspirações de salvação. O fiel que neles se alistava, que se compromelia perante os mesmos, cra obrigádo a cerimônias colclivas, conduzidas por sacerdoles autoritários. Era sclecionado por uma iniciação individual rigorosa que o punha às ordens desses sacerdoles e ao serviço místico da divindade.

Grandes diferenças com os do Império Romano c da Grécia c que respondiam bem às novas necessidades, às vezes contradilóriass das almas. marcavam esses cultos. Chegados a Roma sob forma mais ou menos helenizada, longe de acentuarem essa lendência, tomam no Império Romano um carríler nitidamenle exótico: como para melhor proporem a seus liẹis o benclício das misleriosas sábedorias do Oriente. Em loda religiâo, em todos os meios, a singularidade de seus ritos distinguia os fiéis que, de uma ponla a outra do Império formavam comunidades de ísis, de Cibele e de outros deuses, assegurando-se cada cual de uma graça de salvâ̧ăo c com cuja cerleza cle somente contava no lemplo da divindade que o acolhera.

Roma não deixou de agir sobre as religiócs que a invacliram, mâs de morlo irregular e sob aparências contradilórias: nesse càlinho desmesuratlo, com cfeilo, as conlanninações, involuntairias, cerlamente, cram tão falais yuanto as oposiçóes doutrinírias.

Os grupos religiosos, muitas vezes secretos, tinhaun sua razão de ser na sua própria singularidade. Os cultos orientais accitos sob pressão de fiéis conscienles, viam mais vanlagem em corlar de modo nílido os antigos cullos latinos: cra a condição para o sucesso das mesmas. Mas, em sentido contrário, a proliteração dos lugares de reuniōes exóticàs, respondendo às aspirações espiriluais e utilizando simbolismos análogos, não se lazia sem empréstimos recíprocos c diversás asssimilaçōes.

A reflexão melalísica dos latinos tornava-se lão frouxa yue se preleria, muilas vezes, anles a confusão que a niticlez doutrinária. E se as religiốes do Oriente influíam na religião de Roma, essas mesmas religióes seriam cm seus países de origem influcnciadas pela religiño de Roma. Assim vemos o bétilo (pedra) de Cibelc vindo informe para Roma, feito antropomorfo cm Roma, recebendo a cabeça de uma mulher, sem perder o carríler oriental no seu cullo. Em Palmira, em pleno deserto entre Medilerránco e Eulrales, os deuses puramente semílicos apresentam-se ora como Marle, ora como Ceres e, aindla, como o sol coroado e em seu carro. Na Síria as aparências romanas dos deuses predominam por volla do século IV; o lauróbulo, rilo de aspersãio com o saingue de um touro, vem do Orienle a Roma sem ser accito na Grécia c no sćculo IV volta a Atenas. 


\section{ísıS}

Célebre divindade dos Egípcios, irmã e csposa de Osíris.

Desde o segundo século a.C., os deuses egípcios contavalan admiradores em Roma, priciplamente entre as populaçōes cosmopolitas.

A princípio, as hostilidades do governo foram manilestas: em 58, 53, $50 \mathrm{e}$ 48 a.C. 0 senado mandou lechar templos e destruir imagens e divindades orientais. Em 28 Augusto proibiu a construçăio de um lemplo. As proibiçóes, renovadas por Agripa c Tibćrio, foram abolidas por Calligula. Em 18 consiruíram um templo a isis no campo de Marle. Sob os Antoninos e os Severos sen culto lomou incremento notável. De Roma passou para as províncias, mas sem grande accilação.

O rilual de Ísis cra mais completo yuc o de Cibcle: compreendia duas parles, uma de manhãa coulra à tarcle.

Pela manhã o sácerclole reavivava o logo sagrado, depois de ler retirado o manto que cobria a estálua da deusa. Fazia libações com água yue dizia ser do Nilo. Tuelo isso cra leito a som de cânticos, música de flaula e instrumcntos de percussão. Essa música signilicàva a presença benlecilora da deusa. As cerimônias, em ordem inversá, à larde, deixavam as almas na espera do amanhãi, prontas para ais adlmocslaçōes clos sonhos míslicos.

O culto a Ísis tinha lambém secu calcendário litúrgico dividindo o ano. As principais leslas cram o Nanigium Isidis, a nave de Ísis, e a Imucrnio, a descoberla de Osíris.

A primcira ocorria em 5 de março. Consistia de una grande procissão lluvial que ia do Tibre alce o mar. Os iniciados vestiam roupas brancass; os sacerdoles levavam uma urna com água do Nilo e a imagem da deusa, lodia enfeilada.

A segunda, a do descobrimento do Osíris, marido de ísis, relizava-se, em Roma, no início de outubro. Elc, diziam, linha sido morto por Seilh e seu corpo corlado em pedaços. ́́sis os encontrou lodos e Osíris loi ressuscilado. Lendo sido translormado cm proletor dos mortos. Sua comemoração anual passava do desespero lúnebrè à mais completa alegria.

As cerimônias de Î́sis tinham todass un carailer hermélico e somente os iniciados as comprecndiam bem. A àlmissão ao culto iniciava-se pela cerimônia da purilicação, quando o sacerdole conduzia o iniciado a um lago próximo do lemplo e o aspergia, invocando os deuses. Reconduzido ao lemplo, ouvia os mandamenlos que deveria observar: abster-se de cárnc, de vinho, guardar continência e silêncio. No fim do décimo dia, cra conduzido a um lugar misterioso, escuro e escondido a que somente os sácerdoles tinham acesso. Subitamente a noile se iluminava com fulgores e visōes maravilhosas. Depois, em trajes magníficos, cra apresentado aos liéis; lrazia uma tocha na mão c uma coroa de palmas na cabeça. Vinham, cm seguida, os bannuctes, as danças, as festas, não fallando a licenciosidade caraclerística dessis lestas. Os adeptos de ísis ganhavam, assim, a cerleza de obter a sâlvação após a morte. 

n. 19, R. 67-80, 1991.

A religião de Ísis recrutava cm todas as classes e não visava a clevação espiritual de um grande número; para a maior parıe, ábluções, gesłos, fórmulas, períodos de continência, eram suficienles por si sós, sem compromisso verdadciramente pessoal; a antiguidade das cerimônias encorajava as celebrações meç̂nicas, mas não se pode dizer que fosse uma religião esclerosala: sob scu aspecto imulável ela se deixava levar ao progresso geral da rellexĩo ética e da metalísica. Podemos ler no livro XII das Metamorfoses de Apulcio, no fim do século II, que a submissão aus ritos isíacos não fazia señ̃o exallar um fervor de união com a divindade, uma sensibilidade e confiança de surpreendente frescor de alualidade, pois a iniciação mística do elcito aparece aí mais ainda como apaziguamento de uma alma voltada agora ao serviço da divindade que remediava as inquieludes. Era a essis inquiludes, porlanto, que respondia sobretudo, mas $\mathrm{cm}$ graus bastante diferentes, a religiño de íSIS.

\section{CARACTERÍS'TICAS DE ÍsIS}

Antes de procurarmos, no livro das Metamorfoses de Apuleio, as virtudes e características de Ísis, vejamos o que os arelologislas, i.e., os que estudam as virtudes de um ser, apontam dessa deusa, baseados $\mathrm{cm}$ lextos, em inscrições, não latinos, mas sobreludo cgípcios.

\section{Natureza:}

\subsection{Características essenciais:}

1.1.1 senhora da lerra,

1.1.2 inventora (com Hermes) das escritas hicroglífica e demótica (cursiva dos cgípcios),

1.1.3 instrutora das leis e dos mais antigos costumes.

\subsection{Genealogia:}

1.2.1. Tilha de Cronos,

1.2.2. irmã e mulher de Osíris (com quem deu os cereails aus homens),

1.2.3. mãe de Horos.

\subsection{Cullo:}

1.3.1. fesicjada no dia $1^{\circ}$ do ano,

1.3.2. adorada principalmente pelas mulheres,

1.3.3. senhora de Bubaste (cidade do baixo Egilo).

\section{Onipotência:}

\subsection{Comando do céu:}

2.1.1. separa o céu e a terra, 
v. 16, n. 19, p. 67-80, 1991.

2.1.2. fixa o percurso dos astros,

2.1.3. aloja-se nos raios solares e acompanha o sol.

2.2. Domínio dos elementos:

2.2.1. domina os raios, os ventos, os mares e rios, as cluuvas,

2.2.2. faz surgir os continentes e as illhas,

2.2.3. fixa seus lugares $e$ limites.

3. Poder:

3.1. senhora da guerra e da paz,

3.2. todos cumprem suas ordens,

3.3. ela desfaz todas os embaraços,

3.4. vence o destino.

4. Ensinamentos:

4.1. ensinou aos homens a arte de fazer o pão, suprimindo a antropolagia,

4.2. ensinou a construçāo de casas e abandono das grulas,

4.3. ensinou os socorros: medicina, navegação, arte militar.

Enfim, ela é considerada a inventora e a insırutora da civilização sob três aspectos: moral, social e jurídico.

No texto das Metamorfoses, vamos ouvir, primeiramente, do próprio Lúcio c, depois, da deusa, as qualidades da mesma.

Na sua oração, Lúcio dirige-se à divindade empregando os seguiles termos:

Rainha do céu; Ceres - nutriz, mâe e criadora das colhcilas, lazendo o homem deixar de comer bolotas de carvalho; Vênus que uniu os sexos, dando nascimento ao amor e continuidade ao gênero humano; socorro das mulheres que estão para dar à luz; claridade úmida que nutre as sementes fecundas (met. XI, 2).

Aparecendo a Lúcio, ísis se apresenta com os mais diversos nomes. Ela mesma diz que é: mãe da natureza; senhora dos elementos; origem e princípio dos tempos; divindade suprema; rainha dos mares; primeira entre os habitantes do céu; governadora dos mais altos pontos luminosos do céu; governadora dos silêncios solitários dos infernos; poder único; venerada com os mais diferentes ritos; chamada por múltiplos nomes: mãe dos deuses; deusa de Pessinonte pelos Frígios; Minerva pelos atenienses autóctones; Vênus Pafiana pelos cipriolas banhados pelo mar; Diana Dictina pelos crelas portadores de llexas; Prosérpina Estigiana pelos sicilianos trilíngües; Ceres Acteana pelos habitantes do Elêusis; ainda Juno por uns, Belona por outros, por estes Hécale, por aqueles Rammisia. "Mas os egípcios e os etíopes chamam-me pelo meu verdadiero nome: Ísis" (Met.XI, 5). 

n. 19, p. 67-80, 1991.

\section{A TRA VIESSIA DE I,ÚCIO EA VOL'TA DE LÚCIO}

Muitas obras literárias são descnvolvidas mostrando unna viagem $\mathrm{cm}$ busca de algo, orientada por um ser superior ou movicla por uma vontade, por uma procura.

Podemos cilar, entre oulras:

A busca do santo Graal; a busca do Eldorado; a procura da fonte da juventude;

a busca da lerra prometida;

a Odisscíin, para a volla a ĺlaca;

a Encidla, para a procura da lerra onde se iniciaria a nova raç̧i.

Também a obra Metamorfosess, de Apulcio, é uma busca. Com uma pequena diferenģa, lodavia: os outros lêm um ponto marcaclo onde chegar; Lúcio, não. Basta que cle encontre rosas ou roseiras floridas.

Quando ocorreu o engano, logo no início c Lucio se Iransformou cm asno, cle nāo se tinha informado sobre o gue lazer para vollar a ser homem, mas ouviu quando a bela moça, Fótis, dlisse: "o remćdio não é dilî́cil: logo ao amanhecer irci procurar rosas; basla que cle coma pélalas".

Mas, anles que tivesse chegaldo a manhãa, chegaram os làlrōes c lá se lou Lúcio $\mathrm{cm}$ forma de burro, sem ler comido pélalas de rosa.

E ć a partir dacqui que vamos ver o assno na sua viagem, lendo sempre em mente a desesperada procura de rosis

Por duas vezes Lucio deparou com rosas ou flores pareciclas. Na primeira vez, conforme lemos no livro III - 29, cle nĩo ousou aproximar-se da roscira llorida, pois pensou: "se comesse as rosas, vollaria à forma humana c, diante dos ladrōes, isso pareceria uma coisa diabólica". Ele seria lomado por um mago, feiticciro c. por que não dizer, por um lobisomem (um Versipcles) c o castigo não demoraria a vir.

Oulra oportunidade: ele chegou com os ladröes a um peyueno vilarejo, onde os bandiclos se puseram a conversar com pessoas yue pareciam amigas. Houve até troca de presentes que o burro - Lácio - julgou que lossem lruto de roubo, pois isso cles laziam cochichando entre cles.

Os animais toram aliviados das cargas e deixaclos a pastar livremente. Alrás da cabana dos laclröes havia uma horli. A fome, a falla de costume de comer feno, fizeram com que, em três lempos, cle devorasse um bom lanto de horlaliças, enquanto procurava pelos arredores, yuem sabe?. uma roseira. O lugar cra propício: longe da estrada, altris de peepueno arvoredo. escondielo. Se ele achasse o remédio... Ele cstava, assim, nesse oceano de fantasia. quando, maravilha! avistou uma planta llorida, flores rosa-vivo, alegres. convidalivas. Uma prece ao deus do Sucesso, uma corrida e cle estaria salvo. Mas que desilusĩo! Chegaldo junto à planla, não foram rosals frescas c orvalhaclas yue cle viu. Por pouco não se intoxicou, pois a planta não cra outra senão o lourciro-rosa, planla a que chamamos es- 

v. 16, n. 19, p. (67-8.1), 1991.

pirradcira, cuja sciva lcitosa é lemível veneno para os olhos c as folhas lóxicas para os animais que as comem.

Há loda uma arquilelura, lodá uma progressĩo onlológica alci as rosas cncontraclas com o sacerdote, a partir dessas duas rosas tenladoras e que nós lentaremos explicar, descrevendo a viagem de Luicio.

Somente a escolha da rosá como antíclolo da metamorlose jai ć revelatora e nos leva a uma inlerpretação simbólica: conhece-se a ricjucya do símbolo da rosá como de oulras llores.

É interessante ver a rosa associada à personagem milológica de Aclônis e, porlanto, a um belo milo de morle e de ressurrcição. Enquanlo Adônis morre, fericlo pelo javali, nascem as rosás brancass e anêmonas que se pinlam com o seu sangue ce com o de Alrodite que se lere nos espinhos.

À primeira vista, parcece não haver viagem, läavessia, pois as peripx́cias de Lucio parceem um amontoado de tribulaçōes e avenluras, sem um lïo direlor pereeplível. As siluaçōes são variadas, às vezes conlladitórias: Lucio troca sempre de patrāo e isso lhe modlica a siluaçāio; c brutalizado ápui, mall raltado ali, almcałçado de perder a vida, e isso quase aconteceu quando cle por pouco não ló assado no lugar de um cervo; laabalhá para um moleiro, acionando as rodas pesáadas, padece nas mãos de um jardinciro, lem alguns dias lelizes nas mãos de um padciro, cuja especialidade cra päo-de-mel.

Além desses episódios, há inúmcros outros que são histórias dentro de hislórias, formando uma fábula milésia c esse crrar pelo mundo jamais pareceria um Irajeto com um lio delerminado, oricnlado.

Se nas outras obras há percalços e tribulaçōes que devem ser tramspostos para que o herói cumpra seu destino, nas Metrmorfiose's o que move Lúcio é a curiosidade, é sempre a busca do (juc estai à frentc. levalo per unla reaçẫo puramenle instintiva c não cm lunçāo de uma espiritualidade. de uma ordem recebida.

Lúcio yucria ser um pássaro, isto ć: altravés desse sonho de vôo. cle queria alingir imedialamente uma forma de sublimidade, sem lê-la merecido e sem iniciação. Ele se achat um asno, isto ć: altravés desse animall. humillado. sinbolicantente feclaado numa lorma rudimentar e desvalorizada da vida. É como se cle postulasse c lentassc partir para o sublime - 0 vốo - c cásisc no castigo - 0 asıo -, por não ter passáclo pela iniciação.

Na nossa alnilise vimos, com um pouco de cerleza, que, nas Mfelamorfoses, a viagem ou o trajeto não loma a forma oricntacla que aparece nas outras obras; ela transcreve uma forma de evolução, pois Lucio percorre um itinerairio depois de umá queda na amimalidade allé a promessá de redenção no livro XI.

Pela história de Lúcio, temos claramente a idćia, comum em lodos os esquemas iniciálicos, que o ser deve amadurecer para cvoluir. As quáliclades que Ihe são necessárias para isso, cle não as pode adequirir, a não ser altavés de provas e experiĉncias pessoalis. 

n. 19, p. 67-80, 1991.

Existem ensinamentos (como é o caso da iniciação aos mistérios de Ísis, no livro $\mathrm{XI}$ ), mas eles não podem germinar e desenvolver se não num terreno pronto, devidamente preparado, para aceitá-los.

É todo o significado do sofrimento de Lúcio: não haverá economia de provas para Lúcio trocar aquele descabeçado rapaz dos dois primeiros livros e tornar-se o homem cheio de sabedoria do iniciado aos mistérios de Ísis.

Se em algumas obras as provas ocupam as primeiras passagens, nas Metamorfoses, com exceção do conto de Psique e Cupido, elas se espalham por toda a obra. Essa diferença provém da importância dada a essas provas necessárias para a manutenção do herói: se um oblém seu ápice alravés de umas poucas grandes provas, outros as têm simples, mas que se estendem por toda sua vida. A sucessão de boas e más siluações é imprevisível, reproduz lodas as possíveis que a vida oferece e que Lúcio deve esgolar.

Ele procura diferenciar-se cada vez mais da bestialidade física ou moral que o envolve; ele é sensível; ele percebe que aqueles que o tratam, Iratam-no cada vez melhor. $O$ humano que emerge daquele disfarce animal, não tem mais tanto em comum com o Lúcio de outrora.

É, então, que a noite o surpreende solitário, na praia de Cêncreas e aí se opera um fato mais imporlante do que a Iransformação em asno: no seu sonho vai ocorrer-lhe a revelação de Ísis.

Lúcio cumpriu laboriosamente a parte catártica de sua iniciação. Ele fez parte de seu caminho mostrando-se obediente às ordens do destino.

Falta-lhe, agora, comer as pélalas de rosa. Ele não terá trabalho para econIrá-las. É a recompensa e lodo o trabalho passado ou vivido. Ele mesmo não acredita, mas tem a confirmação por parte da deusa. Uma cesta de rosas ser-lhe-á oferecida, por assim dizer, por um sacerdole, na procissão que ocorreria no dia seguinte. Diz-se oferecida, pois o sacerdote com o cesto de pétalas, virá em sua direção e não achará ruim quando o asno começar a comê-las. A deusa diz: "não tenhas medo; rompe por entre o povo; ninguém se horrorizará, mas lembra-le de que, atć o final de tua vida, terás um compromisso para comigo"

Há a descrição da procissão, de todos que dela participam. Depois da longa enumeração dos participantes, o sacerdote que vem em direção do asno, oferecendo o cesto de flores. Logo que o vê, o asno avança.

Ele descreve a sua transformação, agora em ordem inversa, descreve o seu estupor; pede um tecido de linho para se cobrir.

Vimos, então, uma terrível, mas necessária desintegração do herói, ponto preliminar para a sua reconstrução ontológica.

\section{POR QUE ASINVS AUREVS?}

R. Martin, na Revue des Etudes Latines, 1970, p.332, diz que na Metamorfose temos uma viagem, bem como uma idéia de alquimia 

v. 16, n. 19, p. 67-80, 1991.

Parlicipando de estados regressivos, caminhando e recebendo, às vezes, revelaçöes superiores, Lúcio, que representa a psique humana, chega a conhecer possibilidades inerenles à sua condiçāo.

É o sentido das peripécias, no final das quais Lúcio chega a uma forma de decantação, uma verdadeira metamorfose.

Diz o autor que curets, em latim, pode muilo bem signilicar: ruço, avermelhado.

A cor avermelhada era a cor detestada pelos fićis de ísis. Se o autor the deu a cor ruça, avermelhada, ele queria ter, já na cor, o que, para os fiéis de Ísis, cra a representação dos pecados e das forças do mal.

Porlanto, o próprio lílulo do livro já traz uma significação onlológica, parlicipa de uma natureza afastada de ísis, um ponto de perfeição, para quem a psique humana quer dirigir-se.

Essa ambivalência é notavelmente mostrada pela do termo aureıs: tomado no significado de ruço, avermelhado, ele representa um estado inicial, regressivo; mas, se lhe damos a importância da matéria e nāo da cor, o ouro encontra seu estado sublimado de luz que se torna fim simbólico e em direção do qual volta a busca da alquimia: a busca da perfeição.

Muitas imagens fundamentais de Metamorfoses são assim bipolarizadas.

A luz, símbolo bastante importante nessa procura, carrega-se dessa ambivalência em vários pontos; há, nas Metamorfoses, uma verdadeira e uma falsa luz. Esła é a ruim, artificial, emitida pela lâmpada de Psique ( V 20, 21, 23) ou pela de Panfilća definida já pela sua natureza como ruim. E Milão, marido de Panfiléa, que diz: "ć uma sibila famosa... com essa lâmpada ela observa ludo o que se passa no céu como se fosse um laboralórion.

Há, depois, a luz verdadeira e boa, quer ela se irradic do próprio Amor (met. VI, 13, 21), quer ela se irradie da deusa Ísis: "Em plena noile, vi o sol brilhar como uma luz branca" ( Met. XI 3, lo).

Encontramos, ainda, bivaléncia no próprio nome de Fólis, que por sua etimologia, significa o mesmo que Lúcio: luz. A irradiação que provém de ísis - e da qual o nome do iniciado é como um reflexo - brilha tão forte que eclipsa as luzes imperfeitas ou maléficas como a de Psique ou de Panfiléa.

Também existe um bom uso da luz, o que presta homenagem à deusa; e outro que procura desvendar seus mistérios sem o devido preparo ou contrapor-se a seu poder: é através dessa complementaridade de símbolos aparenlemente oposlos que se exprime, nas Metamorfoses, a mensagem de ísIS.

\section{BIBLIOGRAFIA}

BᄉYET, J. La Religion romaine. Paris, 1969.

FERGUSON, J. The Religions of Roman Empire. lihaca, New York, Cornell Univ. (1976). 
GRIMAL, I'. La civilisation romoine. Paris, Arthaud, 1974.

THOMAS, J. Le dkipasseme'mt du guotidien. P’atris, Les Belles Lettres, 1986.

RESUMÉ: Pour expliquer pourquoi l'écrivain latin $\Lambda$ pulée a cknné à son chef-d'ueuvre le litre de L'Ane doOr, (Asinus $\Lambda$ ureus), l'auteur comment le rôle cxercée par la cléesse lsis dans la destinée de Lucius, le principal protagoniste, et unontre que, comme dans d'autres livres de l'anticpuitć greco-romaine, c'est une recherche yui est conlée, recherche yui culmine avec l'initation du jeune personnage aux mystères de la déesse égyptienne qui lui restilue sa forme humainc (Lucius avait ćlé uransformé en âme). Ce thème mythicu-religieux esı discuté à travers de numbreuses références au panorama sociopolitique el culturel de la Rome cusmopolite de l’épxyue d' $\wedge$ puléc, qui avait importé ct donné abri à un certain numbre de divinités étrangères, comme lsis jusıcoment, ct maintcnant les rcjetail, dans l'intention de rculonner vie au panthéon traditionnel. 